\title{
Collaborative Regional Development and Research in Higher Education: In the Perspective of Quality in a University of Applied Sciences
}

\author{
Rauno Pirinen \\ Laure University of Applied Sciences, Espoo, Finland \\ Email: rauno.pirinen@laurea.fi
}

Received August 30 ${ }^{\text {th }}$, 2012; revised September 26 ${ }^{\text {th }}$, 2012; accepted October $13^{\text {th }}, 2012$

\begin{abstract}
Together universities and universities of applied sciences (UASs) form the higher education system as a dual model in Finland. In this setting, there are three statutory tasks for (UAS): 1) education; 2) research and development (R\&D); and 3) regional development. In this continuum of research, the overall research question is: How can the regional development be understood, designed, defined and actualised in UAS? This study presents the case study analysis that addresses the actualisation of regional development task in the perspective of quality assurance. The analysis includes systematic and empirical data collection and evaluation of quality systems by the Finnish Higher Education Evaluation Council between 2002 and 2012. Here, the repositioning of innovation-driving industry and services, UAS, and government relations take place in quality assurance. The focus is on the reconsideration of the quality system due to innovation networks, co-created innovations, the contributions of lead innovations and regional development that has an impact on social and global improvement. The purpose is that a quality assurance and assessments are vital for regional R\&D, participator’s co-creations, creativity, and regional-international R\&D collaboration.
\end{abstract}

Keywords: Action Research; Case Study Analysis; Co-Creation; Collaborative Regional Development; Higher Education; Innovation-Driving Industry and Services; Lead Innovations; Quality Assurance System; Regional Capabilities

\section{Introduction}

This qualitative analysis investigates how the regional development can be understood, designed, defined and actualized in UASs and in the perspective of quality. The context of study is in regional development of Laurea UAS and the perspective of study is in quality, in such views as: challenges and advances of quality assurance; quality management; quality system; and quality concepts. In the background of study, there is the collectively developed integrative model at Laurea UAS between 2003 and 2012. Here, the integrative model refers to the student-centered integration of higher education, research and development (R\&D) and regional development in the viewpoint of actualizations of study units with funded $R \& D$ projects and within regional R\&D actors such as regional innovation system and clusters (Porter, 1990; Doloreux \& Parto, 2005; Cooke, 2004; Teräs, 2008). The purpose of this analysis is in improvements, challenges and advances of regional development within collaborative R\&D activities in the context of UAS, and the study investigates the integrative concepts in regional viewpoints of changes in professional growth, regional strategy and $\mathrm{R} \& \mathrm{D}$. The unit of analysis is a sample of evidence in UAS where the emphasis is on the phenomenon of regional R\&D. The same unit of analysis was also used in all evaluation transactions, since 2003, and then as a continuum, it complements this analysis. The context consists of actualizations of master, bachelor and degree education in programmes of information systems, security management and services; the outcomes of the analysis are available for the possible dissemination to the higher education domain.

\section{Setting of Study}

This study includes continuums of the five earlier studies, of which includes four reviewed conference articles and one double reviewed journal article, which combine the background work of this analysis (Pirinen, 2008; Pirinen, 2009a; Pirinen, 2009b; Pirinen, Tarkkanen, \& Teräs, 2009; Pirinen, 2012). In this article, the results of the case study analysis that addresses the actualisation concepts of regional development in the perspective of quality assurance systems are thoroughly described. The article includes four parts: 1) analysis of context as introduction, rationale of study, and description of domain ontology; 2) explanation of operational environment; 3) resonance of theories; and finally 4) the concept of evaluation design. The analysis includes systematic and empirical data collection, and in addition, the evaluation data of quality assurance systems by the Finnish Higher Education Evaluation Council (FINHEEC) between 2007 and 2011 is included. Then, this analysis between August, 2007 and December, 2010 addresses the Evaluation of Quality Assurance System (Lampelo et al., 2010) and empirical data collection between 2003 and 2012. The analysis is based on (Patton, 1990; Guba \& Lincoln, 1994; Miles \& Huberman, 1994; Robson, 2002; Corbin \& Straus, 2008). Then, this research is as continuum of earlier action research, which is described in (Pirinen, 2009a), and then the form of this research is a case study analysis as it extends the continuum of multiple case study analysis (Eisenhardt, 1998; Gummesson, 2000; Ge- 
orge \& Bennett, 2005; Gerring, 2007; Yin, 2009).

\section{Perspective of Quality}

The perspective of quality in the context of this study consists of six entities: 1) the internal validity refers to a newly created concept in the actualizations, both parallel and alongside the analyses and methods, models, and new processes; the objective is in ensuring that the new concepts and models are logical, authentic and internally valid in the perspective of actualisations and information systems, security and the service, as well as suitable to the context of UAS. In this study, the concepts of management, quality assurance process and thematic curriculum are described; 2) the construct validity refers to the correct operational measures for the theme being studied; then, the view of construct validity is addressed to the extent "what was to be measured was actually measured" or "does it measure what you think it measures", in this, the concept of evaluation design is presented; 3) the related quality terms authenticity and the transparency of data displays refers to participators' thinking and new ideas to emerge, new models, new services and new information systems; in this, the actualization process is seen as continuum of strategy-process-resultimpacts and its feedback as a) development by success; b) learning by failure; c) development by feedback; 4) in turn, the terms reliability, dependability, or auditability refers to demonstrating that the operations of a study, such as the data collection procedures and $R \& D$ interventions can be repeated with the same results; in this study, the quality assurance process and data collections, such as the follow and evaluation data of UASs (AMKOTA), are referenced; 5) as well in this view, there is a real sense of objectivity such as: the quality-systembased data which is gained directly from the practice, then it is not tainted or manipulated by the perspectives, biases, defences, or experience of participators or other facilitators; then, the samples of evidence are gathered from the concrete evidence and partially from the reality that came from the participators' experience, bringing their assumptions, views, thinking, beliefs, trust, and spirit out with the collective reflection of the data; and the last quality term 6) utilization of the concepts, as the guidance models and an action logic of quality with implementation of regional development and globalization to everyday learning, development, and research activities in UAS refers to the utility of new artifacts, services and methodologies.

\section{Reasoning of General Conception of Quality}

The higher education institution is seen as producers of new knowledge and competences, and users of the latest findings and bodies of knowledge in action, which gives them a role within the "thematic core of the regional innovation system". Their thematic nature comes from their operative action in combining knowledge from several sources, such as lead innovation systems, or institutions such as strategic centers of excellence in science, technology and information and communication technology (ICT) innovations. Certainly, with regional and mutual collaboration in UASs, a body of knowledge is co-created with other organizations to contribute to innovations in industry and society (Pirinen, 2008), e.g. national strategic research agendas (SRA). Then, in this study, the general conception of quality, when formulated in terms of the outcome of inquiry and activity, has something important to say regarding the meaning of inquiry, analysis, activity and domain ontology itself, as well as continuum of previous studies (Pirinen, 2008, 2009a, 2009b; Pirinen, Tarkkanen, \& Teräs, 2009; Pirinen, 2012).

In starting, the actualization of respectable quality faces challenges and opportunities due to shared networked expertise and the integration of a knowledge society and R\&D activities. That statement includes the following contestable issues as triggers of change in UASs, founded from data alongside of data collection since 2003. 1) the regional development task is agreed and actualized in UASs as the third statutory task; 2) the role of external R\&D-based funding is growing and a relative amount of government-based funding is decreeing in UASs; and 3) more shape profiles of UASs and R\&D studies are needed due to different requirements of regional capabilities, professional growth and welfare in the region, in similar ways which are described more detail in (Pirinen, 2012; Rauhala, 2008).

As a consequence of this: 1) a commissioned discursion and power is changing into a co-creative and value-based discursion and power; then 2) the assumption is that an action in UASs would be based on results and impacts in the region and its continuums, trust, responsibility and retentions as the Triple Helix (Pirinen, Tarkkanen, \& Teräs, 2009); 3) UASs would be involved in co-creative and trust-based discursions and R\&D activities in the region; then 4) the role of students of higher education is changing, rather to co-creators of new knowledge and competence than consumers of knowledge in the region; 5) due to the close integration of workplaces and the UAS, an action primarily bridges competences in the first place which produces a new way of using knowledge in action; and 6) in a general sense, external funding is needed to ensure the fulfillment of the three tasks.

In addition: 7) a competition is increasing for the recruitment of students and talent between higher education institutions and global networked actors; 8) higher education institutions have different emphases, and they are regionally profiled according to co-created regional R\&D strategy and strategy-based profiles; then 9) higher education institutions are collaborators in contributing to the regional innovation system and regionally nested clusters and knowledge reserves in the region; then 10) higher education institutions particularly keep co-creation and innovation processes alive through regional, national and global interactions, as trigger, driver and enabler to collaboration; 11) as a role, higher education institutions are co-incubators of entrepreneurial skills and value makers for new competences and involved in sharing of activities in emergent value networks; then 12) regional interaction collaborates Student-Centered $R \& D$ in inter-operative ways and shares the regional-national R\&D capabilities and interests. In this union, as fulfillment of respect; 13) the quality assurance systems would include more or less networked results, impacts, consequences and analysis of over regional actors and the UAS itself.

\section{Brief to Context and Its Domain Ontology}

In this operational environment, the term "quality" is understood as the suitability of procedures and systems in relation to strategic objectives; then the achievement of objectives is assessed though the evaluation areas specified in the Strategy Implementation Plan. In turn, the term "quality assurance" consists of procedures, processes and systems used to guarantee 
and improve the quality operations. The "quality assurance" is carried out using jointly defined, operation-enhancing and appropriate procedures, methods and tools. In this, the term "quantitative research" can be handled numerically; these numbers are interpreted and described through qualitative lenses, where "qualitative research" is a method that examines people's world or action in a descriptive way; representing the experiences of people involved (Patton, 1990; Robson, 2002).

This context also provides insights into the interpretation of the term "innovation" in this regional collaboration and operational environment. Starting from Schumpeter's (1939), five meanings of the term "innovation" were: new goods, new processes, new markets, new sources of supply of new materials, or a new organizational status. Tichy (1998) relates that "innovation is as organizational capability which includes: scientific; technological; socioeconomic and even cultural aspects." Geffen and Judd (2004) advocate and extend that "the successes of commercialization and commercialized advantages are major determinant of innovation.” As used in this study, Galanakis (2006) proposed a broader definition for the term "innovation": "the creation of new products; processes; knowledge or services by using new or existing scientific or techno-logical knowledge, which provides a degree of novelty either to: the developer; the industrial sector; the nation or the world; or to succeed in the market place."

The related term "lead innovation" is often based on novel technologies or new services, which are targeted at value-added chains with great economic potential (Pirinen, 2008; Etzkowitz \& Leydesdorff, 1998). The lead innovations are described in a variety of features such as: 1) positive effect on economic growth and employment; 2) orientation toward value-added chains with high economic potential; 3) the creation of new jobs and the strengthening of the innovative potential of Industry; 4) enhancing strengths; 5) conquering new markets; 6) orientation toward social demands; 7) networking and clustering of present and future activities; 8) completed projects and infrastructure; and 9) risk assessment (Porter, 1990, 1998; Etzkowitz \& Leydesdorff, 1998; Harmaakorpi, 2004; Teräs, 2008).

According to Harmaakorpi (2004), the five "regional capabilities" in this operational platform would be: 1) leadership capability; 2) visionary capability; 3) learning capability; 4) networking capability; and 5) innovative capability. Here, the term "capability" refers to the power and ability to do something, e.g. as the regional capabilities to in-crease the productivity of a region. In the actualizations of study units, the integration includes clusters (Porter, 1990; Teräs, 2008) and regional innovation systems (Doloreux \& Parto, 2004; Cooke, 2004). Doloreux and Parto (2004) state that the concept of a regional innovation system is understood as a set for integrating public and private interests, formal institutions and organizations, as well as relationships for conducting generation and dissemination of new knowledge. Cooke (2004) defines a regional innovation system: it consists of integrating knowledge generation and exploitation to other regional, national and global systems for commercializing new knowledge. According to Cooke, "It is limited in scenes of geographical existing, as well as meaning of regional was related as nested territorially beneath.”

\section{Operative Environment}

As in the above reasoning, the task of regional development was understood to be one of the main tasks of the Finnish UASs (Rauhala, 2008; Pirinen, 2008; Kallioinen, 2007). In education and research, a "third task" was added (Finnish Act, 351/2003), involving services for communities' regional development. The outreaches are then: co-creation of innovative activities; knowledge transformation; and bringing the concepts of science and innovation closer to citizens by Living Labs and Regional Innovation Systems (Pirinen, 2012). In this view, a knowledge society creates shares and uses knowledge for the well-being of its people (Pirinen, 2008). Creating competence and professional growth takes place by using a body of knowledge in action (Pirinen 2008; Nunamaker et al., 1990-91). In this collaboration, the term "networked expertise" refers to competences that arise from social interaction, knowledge sharing, and collective problem-solving, and it is embedded in the shared competence of communities and organized groups of experts and professionals.

As one result of the analysis, cognition and intelligent activity and knowledge reserves are not limited to an "individual's mental and as consumers' processes”, but also on socio-culturally developed cognitive tools; this composes a continuum: 1) individual's development; 2) organization's development; and 3) region's development. This continuum of professional growth and R\&D collaboration is investigated through quality system. The Onion Model, as a screen of this actualization and environment, is described in Figure 1.

Beginning from the outer edge of the Onion Model, in Figure 1, the most macro area is represented as "international" or "global". The next sphere is environments, as "national" or "regional”. Next come cluster networks and innovation systems which include cooperative actors and national and international R\&D projects. Then, finally, at the micro-level, there are courses as actualization of study units in the thematic continuum, which bridges the regional R\&D agenda, strategies, cocreated profiles, R\&D activities and quality system to this union. This operational environment was gradually developed into an operational model, where Student-Centered R\&D integrates professional growth and lifelong development and learning.

As a next result of the analysis, drawn since 2003, the focus of globalization shifts from the traditional situation, where students moved between work places and universities, into an R\&D agenda, lead and theme-based on joint activities, where international expertise, as universities share knowledge and ideas over distance and borders with R\&D collaboration as a pipeline. In this view, UAS focus on the expertise and regionally oriented form and profiles of higher education; it cooperates with communities of work and then business, industry and services, and in the delimited context of this study, their degrees are designed to meet the changing and agile requirements and development needs of the communities of work, having a clear expertise emphasis and qualifying graduates for various duties. In the view of quality in the Onion Model, the unit of analysis, such as sample of evidence, can produce transparency in continuum of: 1) quality implementation and confirmation; 2) development of operations and strategies; and 3) research interest, which links industries, government, academia, finance and institutions for R\&D collaboration.

As a second category of analysis, the operative environment in case, at Laurea UAS does not have separate R\&D units for actualization of its R\&D duty. The R\&D activities and actualization have been strategically integrated with Student-Centered 


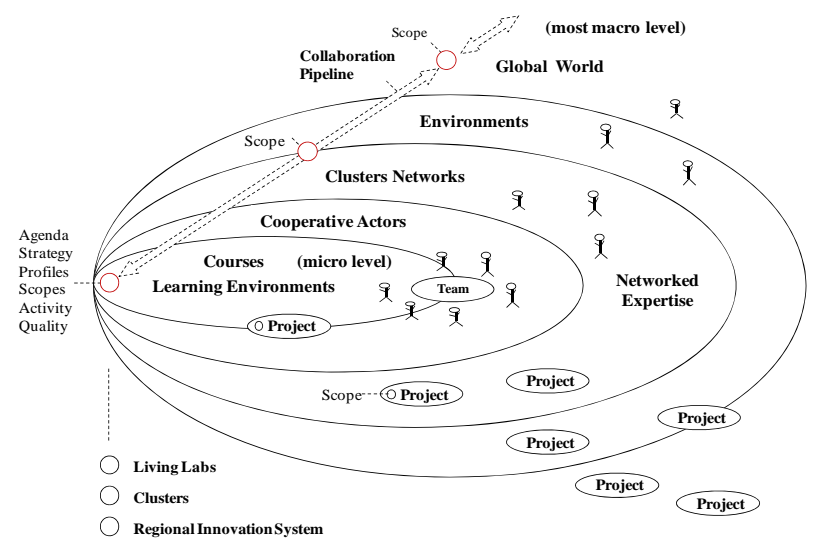

Figure 1.

The onion model.

$R \& D$, professional growth and integrated learning. Then, this strategic decision was called to the integrative model since 2003 (Pedagogical Strategy, 2002, 2007; Pirinen, 2008).

\section{Resonance of Theory to Concepts}

This part presents the used theories in the collaborative regional development, R\&D and education between 2003 and 2011. The theoretical consideration of quality includes: 1) the Gibbons" "mode-2" in the perspective of new production of knowledge and mode of management (Gibbons et al., 2008); 2) the setting of the linear quality management model and its theoretical background; 3) the regional development theories such as the Triple Helix (Etzkowitz \& Leydesdorff, 1998); and then 4) the theoretical groundwork of the thematic curriculum which bridges strategic R\&D agenda, regional profiles and learning scopes to the continuum of syllabus-curriculum-regional-national-international relations, interactions and studies. These theoretical viewpoints are utilized in practice and then empirically tested since 2003. Here, the biggest advantages and challenges of the used theoretical groundwork are presented. The targets of this theoretical part are in increasing trustworthiness, understanding and internal validity.

\section{Production of New Knowledge and Management Modes}

There are two suggested management approaches for collaborative $\mathrm{R} \& \mathrm{D}$ in view-points of integration and knowledge co-creation (Gibbons et al., 2008): the disciplinary "mode-1" and the intellectual "mode-2". Gibbons' "mode- 1 " is based on a disciplinary setting, where the creativity of an individual is the driving force of development and is operated through disciplinary structures of identifying and improving the management and that collective perspective. This "mode- 1 " includes control aspects as the consensual figure of the scientific community. Gibbons' "mode-2" is the intellectual quality setting in management. Here, the creativity is collective as a group co-creativity phenomenon with the individual's contribution. In "mode-2," the management is being exercised as a socially extended process which accommodates a variety of interests in a process. Gibbons et al. states that these two imperative systems coexist in the recent and future actualizations of the knowledge creation processes: 1) "mode-1", which represents "the ideas, methods, values and norms that have grown up to control the diffusion of the Newtonian model of science to more and more fields of enquiry and ensure its compliance with what is considered sound scientific practice" (Gibbons et al., 2008: p. 167); and "mode-2", meaning "knowledge production carried out in the context of application and marked by its: transdisciplinarity; heterogeneity; organizational heterarchy and transience; social accountability and reflexivity; and quality control which emphasizes context and user-dependence; the results from the parallel expansion of knowledge" (Gibbons et al., 2008: p. 9). In our view, the term "transdisciplinarity" involves a research strategy that crosses many disciplinary boundaries to create a holistic approach; it applies to research efforts focused on problems or scopes that cross the boundaries of two or more disciplines, such as research on effective information systems; the term "transience" describes a temporary or shortterm activity; transient data is a type of data that is relevant for a limited time period; creative cycles, trials and ideas are often quick and temporary in nature; and in turn, the related term "transparency" is allowing actors to see through so that objects and activities behind can be seen clearly.

As one implied result, the used management model shares the insider positions and role, as well as participating intensively in the management of R\&D and regional collaboration. This combined leadership and management, as a union of Gibbons' "mode-1" and "mode-2", affects quality in such as the planning of R\&D agenda, co-creation of regional strategy, forming of profiles, and leadership of R\&D activity. In this case, the model of management was based on a bottom-up, visionbased and relationship management model; it was also based on an orientation and management culture and philosophy, where the management focus is on variations of power and authority relations and in the relationship management. The management model was then suitable for enabling agile scopes in the R\&D and learning processes, so that the ecosystems of different stakeholders can come up with new creative ideas. The focus of management was on a co-creative discursion and its power, such as enablers and emancipatory activities.

As analyzed guidance from Gibbons et al. to the design of the quality assurance system: it is noteworthy that future quality systems, as based on the integration of "mode-1" and "mode2 ", would include an impact analysis over a region for 1) development by success; 2) development by feedback; and 3) learning by failure. Then, a management and one purpose of quality policy as "mode- 1 " is that it does not hinder creativity in the R\&D integration of future and regional development. As reasoning, an atmosphere and spirit of management would encourage, motivate and facilitate active and agile action as "mode-2" advances; then, in this setting, emergent and creative activities by internalization and externalization of vital trust and openness in a transparent culture of management would be supported by the integration of "mode-2" and "mode-1" (Pirinen, Tarkkanen, \& Teräs, 2009; Pirinen, 2012).

The future regional collaboration and management model with externally funded and evaluated R\&D also needs greater flexibility in the future because the amount of different standards used by various R\&D actors, the European Union and other institutions, are increasing and entering into the collaborative and regional $R \& D$ processes. "These standards are required to be frequently revised, and this change in turn requires institutional flexibility” (Gibbons et al., 2008: p. 167), ability to change, and trust-based management (Pirinen, 2008; Pirinen, 2009a; Pirinen, 2009b). 


\section{Concept of Quality Assurance Process}

In this case, the rationale of the selection of quality management and data collection process model, in the context of study at Laurea, lays in the fact that there are 500 faculty members, 8000 students, and about 70 co-operators, which are all using the quality assurance system for data collection, quality implementation, and confirmation, as well as development and verification purposes. In the selection process of the quality assurance and management model, one of the most well-known and evergreen models was the Deming-Shewhart cycle or PlanDo-Check-Act (Shewhart, 1939; Deming, 2000), which was considered to be light enough to use and meaningful for dissemination and co-operative action; but nevertheless, it was useful and inter-operative in the context and has views of quality and management that include vision-strategy-based management and development. The actualization of quality steps as a quality assurance process is described in Figure 2.

In the context of this study, the steps of quality assurance are actualized as: 1) Plan: Planning the activities, i.e. what should be done, what results should be achieved, and what is necessary to change in the actualization? This concerns the co-creative and participative nature of planning and the implementation of definitions into the design and optimization of the quality sigma; 2) Do: Making the actualization and implementation according to the plan, actualizing and implementing interests, and cooperating and participating, as well as generating new knowledge from the creation perspective of doing, e.g. the learning and regional development process; Next, 3) Check: Checking the activities and the results achieved, which involves development, the research interest, the knowledge creation interest (e.g. the reviewing of research reports and updating of the syllabuses), the implementation of analysis, measurement and verification interventions in the quality sigma; 4) Act: Acting systematically; taking into account the observations and results of the checking, regarding the consequences and especially implications of the actualization for the next stage and the body of knowledge, e.g. the binding of new theories and writing of a draft for the next syllabuses. The Act responds to the question of management about the continuation of some activity or falsification as to forward future (Shewhart, 1939; Deming, 2000).

\section{Sight of Triple Helix}

In the operational environment of study, the professional

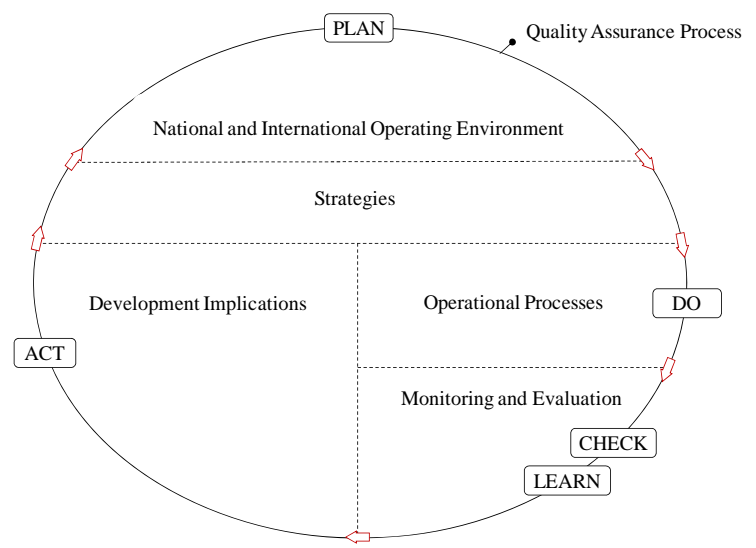

Figure 2.

The quality assurance process. growth, development and learning activities were based on understanding, design, building, improving and evaluating services, artifacts, methodology and technology that can exist in an appropriate instance of regional R\&D concentrations, which are often extended outside of traditional classrooms. This viewpoint includes living labs as schools which collaborate with R\&D institutions and Strategic Centre of Science (SHOKS) with industry, the service sector and government. This sight is known as the Triple Helix (Etzkowitz \& Leydesdorff, 1998; Etzkowitz et al., 2000). The focus of the co-creative Triple Helix would be on the creativity and innovations which are produced through the dynamics of interactions and communications among academia, industry, and government and on the social mechanisms of selection, variation, and retention responsible for their evolution as sectors. In our view, the objective of actualization of the Triple Helix model was to realize an environment with innovativeness, consisting of UAS and university spin-offs and initiatives for knowledge-based economic development, and strategic alliances between the actors of the regional Triple Helix (Pirinen, Tarkkanen, \& Teräs 2009; Pirinen, 2009a).

The setting of quality actualization is in furthering the regional development, competence-based competitive assets and spinning up entrepreneurship in student-centered professional growth. This view of collective learning focuses a student's own and collaborative creations, which effects as thematic scopes and are related to the strategic focuses of region and actualised as nested within regional clusters and innovation system (Doloreux \& Parto, 2004; Cooke, 2004; Fränti \& Pirinen, 2005).

As orientation to quality actualization and development: according to Finland's National Innovation Strategy (2008), the four basic selections are: 1) innovation activity in a world without borders, active Finnish participation and considerable influence in global knowledge networks, as well as its citizens' high international mobility and the country's attractiveness relative to globally leading alternative locations for innovative activity; 2) demand and user orientation as a basis for innovative activity, better attendance of customers', consumers', and citizens' needs and a higher involvement of users in innovation processes; 3) individuals and communities creating innovations, providing better abilities and more incentives for individuals and entrepreneurs to innovate; and 4) systemic approach-interdependence of success factors; more broad-based innovative activity promoting renewal and structural changes.

\section{Concept of Thematic Curriculum}

As a continuum of the quality assurance process, the term "thematic" is addressed to the continuum of syllabus-curriculum-regional-national-international relations. The thematic region, thematic living-labs, novel R\&D activities, thematic curriculum, and thematic actualizations of study units have corresponding interests in the R\&D agenda. This refers to students' learning being related to a body of dynamic and agile themes for thematic studies, which are important to regional, societal, and innovation systems. In this inter-operative way, research areas of the R\&D agenda and a regional innovation system interact with the generation of new competences and regional capabilities in the actualizations of UASs.

This logic and steps of the thematic actualizations are described in Figure 3 which is located to the end of this chapter. 
The first step of actualization in Figure 3, after co-created strategy consists of traits and characteristics that constitute the foundation for learning and collaborative R\&D and represent the natural form of individual student or groups of students, where further experiences can be co-created. Differences in personalities and characteristics explain why people follow different development and learning experiences and ideas, as well as acquire different levels and kinds of skills, abilities and knowledge.

The second step consists of skills, knowledge and competences, which are developed through R\&D-based learning experiences, broadly defined to include work and participation in community affairs and innovation systems. In this, scaffolding is a supporting process or structure for learning or training something that is already known, e.g. training of competences, sharing of knowledge, model-based learning and training. The competences within different contexts require different bundles of skills and knowledge, and demonstrations are the mid-range results of applying and proofing of competences.

The integration of learning and collaborative R\&D particularly challenges assessment. A student may have a genuine workplace competence assessment setting in slightly different ways, depending on the context, which requires teachers to have a collective familiarity of competence for assessment, prominent as well as a self-, group- and sample-based assessment would be used for recognizing of lessons to be learnt. This is illustrated in check-proof of-evaluation part of Figure 3. The one advantage of thematic curriculum is that strategy of UAS becomes active part when it co-creates and decides R\&D profiles with other regional $R \& D$ actors. The $R \& D$ profiles addresses on what UAS can explore and experiment with changes in how it can compose and react to internal and regional $R \& D$ demands. This setting improves: 1 ) an expanded R\&D collaboration in region; 2) extending funding base on UAS; 3) regional motivation of R\&D scopes; 4) an integrated trust and spirit of Triple Helix in region.

\section{Concept of Evaluation Design}

In light of evaluation steps and quality, there is no easy and single way of determining construct validity in collaborative R\&D activities as stated in (Patton, 1990; Miles \& Huberman, 1994; Robson, 2002; Corbin \& Straus, 2008). Here, the con-

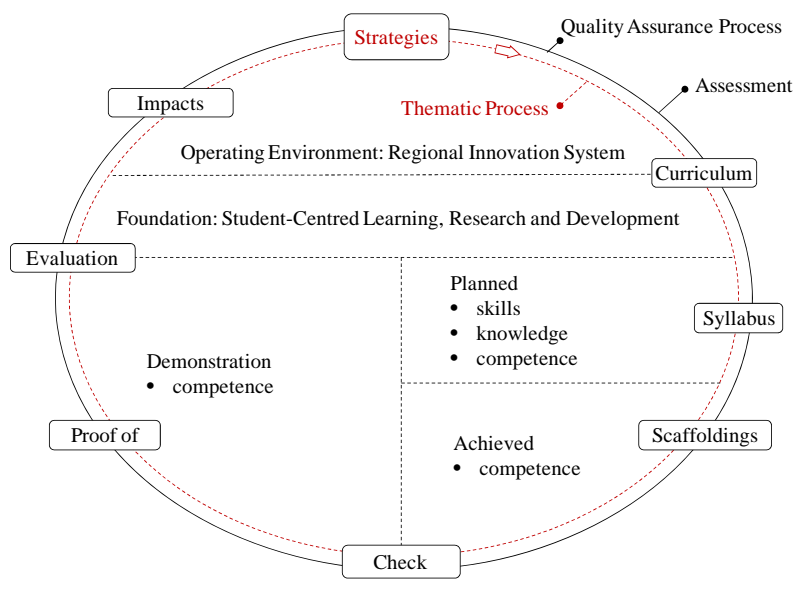

Figure 3.

The concept of thematic curriculum. struct validity refers to the correct operational measures for the theme being studied. The view of construct validity is addressed to the extent "does it measure what you think it measures” as (Robson, 2002) asked. In this study, the analysed framework that "what was to be measured" is presented in form of categories and continuums in Figure 4.

This proposal to future Evaluation Design of actualizations includes both qualitative and quantitative data (AMKOTA) as which would be interpreted in forms of 1) new start-ups; 2) results; 3 ) direct impacts; impacts of R\&D activity after 3 - 5 years (a); indirect impacts (b); and iterative feedback (f) in Figure 4. Then, further $R \& D$ of a "higher region" measure instruments and forecasts of proactive regional capabilities are required. The current result estimations and measures, which are related to $R \& D$ and regional development are mainly defined, maintained and co-created by the Ministry of Education and Culture and network of UASs. In this domain, the AMKOTA is the statistical data base containing fundamental data of UAS activities. The statistics of completed credits are compiled by calendar year and by field of education. Completed credits have been completed with a passing grade in youth and adult education, leading to a bachelor's degree and education leading to a master's degree. The data of AMKOTA are requested directly from UAS and obtained from Statistic Finland. The AMKOTA database is administered by the Ministry of Education and Culture. Here, the strength of the construct validity addresses the statistical nature of the analyzed units, such as: the theses which are based on projects or R\&D, the publication number produced, and the external funding of R\&D. In this analysis, the one identified weakness of construct validity lies in the estimation nature of used analyzed units, such as the number of credits completed in R\&D, which one is the criterion-based estimation in actualization by teachers; however, it is useful in the perspective of motivation and dissemination of $\mathrm{R} \& \mathrm{D}$ and regional development in UASs.

The analysis also has significant implications for further research, the development of multiple methods in multiple environments "over actors of a region" or "from discursions and forums to federation" for the measuring of impacts, which are described as circles (a-b) in Figure 4, because the impacts would exist in actualization, research environment, working life or regional-societal networks, and during the time of actualization of study unit or long after that. Measuring of the impacts (a-b) is useful in perspectives of: 1) development by success; 2) development by feedback (f); and 3) learning by failure.

In this evaluation design, the one ontological finding for the future is the promising and relatively new key term a "quality robe". It is drawn for human-centered ways of information gathering about the students- and users-centered approaches. In this, quality screen, the "quality robe(s)" would be as instances of the design robes, such as approach to user-centered design for understanding human phenomena and exploring design opportunities; the probes are explorative, design-oriented and based on self-documenting; they aim at revealing users' personal perspectives to enrich design and support empathy (Mattelmäki, 2006). Then in a similar way, in this quality screen, the "quality robes" would be useful in the quality design and can be related to the terms of activities, for example: a quality entity in the scope of study; self-assessment; quality of proofing (Nunamaker et al., 1990-91); group-assessment; balancing of complexity; and used in perspective of the design of human-centered quality in a general sense. 


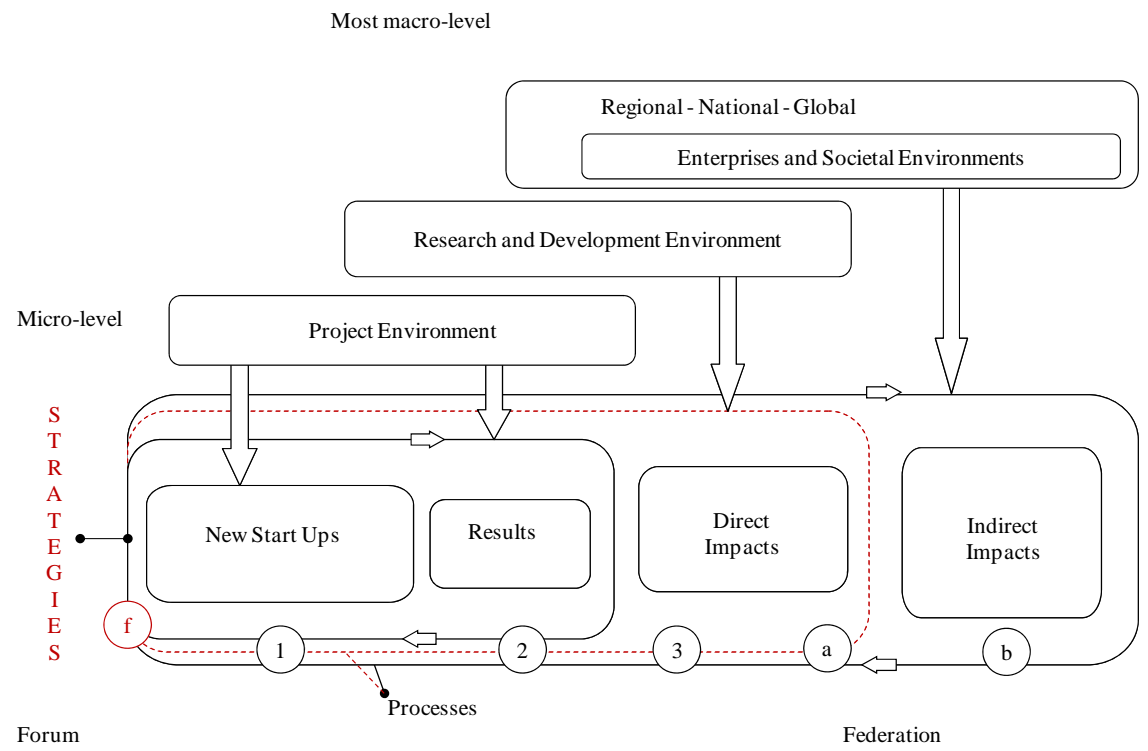

Figure 4.

The evaluation design of actualizations.

\section{Conclusion}

The purpose of this study has been to describe the analyzed concepts of regional development in a UAS in the perspective of quality. The study furthered the continuum of the five earlier studies and then addresses the comprehensive research question: How can the regional development be understood, designed, defined and actualized in a UAS?

In this analysis, the concepts for understanding, designing and actualizations are presented in the perspective of quality and a quality assurance system in higher education. The related benefits of the study are: 1) interests of quality implementation and confirmation; 2) benefits of strategy-based research and development for actualizations; 3) problem-solving interests; and 4) allowing transparency to research interests (by outsiders).

Several conclusions emerge: 1) the advantages to domain ontology in where the key terms were bridged to empirical evidence; 2) the operational environment was investigated and presented in the perspective of quality and empirical evidence; 3) the theoretical binding was explained in viewpoints of past experience and quality in actualizations of a UAS; 4) the concept of a quality process was described in sight of integration of regional development and for improvements of future actualizations of authentic study units in the UAS context; 5) the concept of thematic curriculum for integration of "curriculumsyllabus" and "regional-national interest" as continuum was presented; and finally 6) the concept of evaluation design was analyzed, which can produced the scenery to the future improvements, such as setting of measuring of regional and national impacts. This type of analysis is highly complementary to incremental theory building from previous regional theories such as integration of the Triple Helix and co-creation theories in a higher education context. The used form of multiple case study analysis is useful in early development cycles, for example in producing understanding of the logic of action and development of meta-models to quality assurance system.

The study has significant implications for further research of quality in regional context. The first implication addresses the collaborative and co-creation activities of regional development. This question would extend to: 1 ) what are the characteristics of the dynamic and core capabilities in a region; 2) how would the regional capabilities be linked to the competences, curriculum, and R\&D and innovation activities within quality assurance; 3) how could future research be used more effectively in exploring potential regional development and co-creative environments, such as living labs and last-mile research in perspective of quality; 4) how could enough shared and co-created vision be built in a region, the regional development network consists of actors with different backgrounds and quality aims; 5) how can we co-created a portfolio of strategies in a region to enable a successful future development path to take place; and 6) how should the significance of regional innovation networks be thoroughly analyzed as part of regional, national, and sectorial innovation systems with collaboration and $R \& D$ activities in perspective of quality?

Second, the development of organizational culture, agilityprofile relations, and trust-commitment-based management between all actors would be in the interests of future research of quality integration. The implication in this study includes two relative different views: 1 ) how to understand the everyday line management quality in this situation; and 2) how to conduct and save agility-, trust-, motivation-, creativity- and vision-based profiles, triggers, drivers, and enablers in a higher education with its collaborative networks.

Third, the study has implications for further research for a deeper understanding in the measuring of results and impacts as evaluation design; the future research question would include: 1) how to understand conceptualization of information and its quality in the union of regional innovation networks and higher education; 2) how to measure achieved impacts such as longitudinal impacts over regional actors in the perspectives of quality; and then 3) how to manage the quality of knowledge growth: even national or regional innovation system or higher education can't control or utilize the continuously expanding knowledge growth and increasing information flow. 


\section{R. PIRINEN}

\section{REFERENCES}

Cooke, P. (2004). Introduction. In P. Cooke, M. Heidenreich, \& H.-J. Braczyk (Eds.), Regional innovation systems: The role of governance in a globalized world (pp. 1-18). London: Routledge.

Corbin, J., \& Strauss, A. (2008). Basics of qualitative research: Techniques and procedures for developing grounded theory. Thousand Oaks, CA: Sage Publications.

Deming, E. (2000). Out of the crisis. Cambridge, MT: Institute of Technology Press.

Doloreux, D., \& Parto, S. (2005). Regional innovation systems: Current discourse and challenges for future research. Technology in Society, 27, 133-154. doi:10.1016/j.techsoc.2005.01.002

Eisenhardt, K. (1989). Building theories from case study research. Academy of Management Review, 14, 532-550.

Etzkowitz, H., \& Leydesdorff, L. (1998). The endless transition: A "Triple Helix" of university-industry-government relations. Minerva, 36, 203-208. doi:10.1023/A:1017159001649

Etzkowitz, H., Webster, A., \& Regina Branca Cantisano, T. (2000). The future of the university and the university of the future: Evolution of ivory tower to entrepreneurial paradigm. Research Policy, 29, 313330.

Fränti, M., \& Pirinen, R. (2005). Tutkiva oppiminen integratiivisissa oppimisympäristössä. Vantaa: Laurea Publications.

Galanakis, K. (2006). Innovation process: Make sense using systems thinking. Technovation, 26, 1222-1232.

doi:10.1016/j.technovation.2005.07.002

Geffen, C., \& Juddb, K. (2004). Innovation through initiatives: A framework for building new capabilities in public sector research organizations. Journal of Engineering and Technology Management, 21, 281-306. doi:10.1016/j.jengtecman.2004.09.002

George, A., \& Bennett, A. (2005). Case studies and theory development in the social sciences. Cambridge: MT: MIT Press.

Gerring, J. (2007). Case study research principles and practice. Cambridge: MT: Cambridge University Press.

Gibbons, M., Limoges, C., Nowotny, H., Schwartzman, S., Scott, P., \& Trow, M. (2008). The new production of knowledge. Thousand Oaks, CA: Sage Publications.

Guba, E., \& Lincoln, Y. (1994). Competing paradigms in qualitative research. In N. Denzin, \& Y. Lincoln (Eds.), Handbook of qualitative research (pp. 105-117). Thousand Oaks, CA: Sage.

Gummesson, E. (2000). Qualitative methods in management research. London: Sage Publications.

Harmaakorpi, V. (2004). Building a competitive regional innovation environment: The regional development platform method as a tool for regional innovation policy. Doctoral Dissertation, Lahti: Helsinki University of Technology Department of Industrial Engineering and Management.

Kallioinen, O. (2007). The competence-based curriculum at Laurea. Vantaa: Laurea Publications.

Lampelo, S., Kainulainen, S., Turunen, J., Viljanen, J., Yanar, A., Mattila, J., \& Saarilammi, M.-L. (2010). Laurea-ammattikorkeakoulunlaadunvarmistusjärjestelmänauditointi. Publications of the Finnish Higher Education Evaluation Council.

Mattelmäki, T. (2006). Design probes. Doctoral dissertation, Vaaja- koski: University of Artand Design Helsinki.

Miles, M., \& Huberman, M. (1994). Qualitative data analysis: An expanded sourcebook. London: Sage Publications.

Nunamaker, J., Chen, M., \& Purdin, T. (1991). Systems development in information systems research. Journal of Management Information Systems, 7, 89-106.

Patton, M. (1990). Qualitative evaluation and research methods. London: Sage Publications.

Pirinen, R. (2012). An action research approach: The actualisation of the three statutory tasks: Education, research and development, and regional development. International Journal of Innovation and Regional Development, 4, 79-95. doi:10.1504/IJIRD.2012.045142

Pirinen, R. (2009a). Integrative action in higher education, industry collaboration and regional development: An action research approach. Proceedings of ICEIRD 2009. Thessaloniki: Inderscience Publishing, 221-230.

Pirinen, R. (2009b). Integrative learning environments in perspective of globalization case: Globalization models and effects in higher education. Proceedings of International Multi-Conference on Engineering and Technological Innovation (IMETI 2009), Orlando: International Institute of Informatics and Systemics, 156-161.

Pirinen, R. (2008). Integrative learning environments in perspective of regional development. Proceedings of Pascal International Conference, Limerick: University of Limerick, 1-10.

Pirinen, R., Tarkkanen, J., \& Teräs, J. (2009). Integrative action models in regional development: Applied triple helix. Proceedings of Triple Helix XII Conference, Glasgow: University of Strathclyde, 1-6.

Porter, M. (1990). The competitive advantage of nations. New York: Free Press, 1990.

Porter, M. (1998). Clusters and the New Economics of Competition. Harvard Business Review, 76, 77-90.

Rauhala, P. (2008). Activities in Finnish universities of applied sciences promoting regional development. In Laine et al (Eds.), Higher education institutions and innovation in the knowledge society (pp. 95-101). Helsinki: Arene, Nord Print.

Robson, C. (2002). Real world research. Oxford: Blackwell Publishing. Schumpeter, P. (1939). Business cycles: A theoretical, historical and statistical analysis of the capitalist process. New York: McGrawHill.

Shewhart, W. (1939). Statistical method from the viewpoint of quality control. New York: Dover.

Tarkkanen, J. (2009). Application for the center of excellence in education evaluation starting 2010. In R. Hemmilä (Ed.), Student-centered r\&d work integrated in learning: Center of excellence in education for 2010-2012 (pp. 5-24). Espoo: Laurea University of Applied Sciences.

Teräs, J. (2008). Regional science-based clusters: A case study of three European concentrations. Doctoral dissertation, Oulu: Oulu University Press.

Tichy, G. (1998). Clusters: Less dispensable and more risky than ever. In M. Steiner (Ed.), Clusters and regional specialisation (pp. 226237). London: Pion Limited.

Yin, R. (2009). Case study research design and methods. London: Sage Publications. 